\title{
AFETOS À SARJETA: O ENTRE-LUGAR DO TEXTO E DA IMAGEM
}

\author{
Alexandre Linck Vargas*
}

\begin{abstract}
Resumo: Uma teoria dos afetos à sarjeta. No intuito de apreender com algum rigor a qualidade-potência do afeto, este artigo propõe o estudo de caso da relação entre texto e imagem, sobretudo nas histórias em quadrinhos. Deste modo, procura-se dar suporte para as questões de identificação, saberes e lugares de acontecimento dos afetos no entremeio da palavra escrita e da imagem figurativa. Por essa razão será oferecida a noção de sarjeta, lugar de passagem de alguma coisa a outra, intervalo onde um acontecimento invisível pode ser visualizado. É pelo rosto do afeto impresso à sarjeta da relação texto-imagem que essa investigação partirá.
\end{abstract}

Palavras-chave: Afeto. Sarjeta. Quadrinhos.

Uma teoria dos afetos impõe-se à tarefa de vasculhar a sarjeta. Mas não se trata da sarjeta no sentido chulo - ou, ao menos, não somente. A sarjeta é um entre-lugar, o espaço de acontecimentos que aparentemente se perdem de vista de uma passagem à outra. Por essa razão, caberia a uma teoria dos afetos um apreço à sarjeta: pois é nela que uma ação invisível pode ser visualizada. Essa imagem da ação do afeto, da imagemafecção, da imagem ela mesma afecção, Gilles Deleuze se ocuparia em $A$ ImagemMovimento, de 1983, a partir de uma investigação do rosto. Isto é, rosto enquanto aparição dos afetos. Contudo, o rosto, seja no seu contorno, seja na sua expressividade, não é uma exclusividade do ser humano - coisa que a procura pela fotogenia cara ao cinema francês dos anos 1920, sobretudo em Jean Epstein, ainda parece ser o exemplo máximo. O afeto é, portanto, segundo Deleuze, uma singularidade, ente único, indivisível, independente de qualquer espaço-tempo determinado ainda que seja criado a partir de um. Afeto enquanto novidade, constituído de qualidades-potências que exibem um rosto. Assim sendo, se o afeto é o rosto, este não é uma parte de um corpo, ele é o próprio corpo.

O risco, contudo, de se supor um rosto para a imagem dos afetos é a fácil associação de que o rosto possui para a ideia de identidade. Em uma época de avatares e fotos de perfil, o rosto é o principal traço identificatório. Por essa razão, é preciso reafirmar o seguinte: o rosto de que Deleuze nos escreve não é uma identidade. Pelo contrário, está para antes da identidade, posto no que seria o conceito semiótico de primeiridade, da qualidade pura ainda aberta, da qualidade ainda prenha da indecidibilidade da potência. Desta maneira, a sarjeta seria o nome — sempre provisório e somente metodológico do lugar onde os afetos ganham rosto, onde aparecem ainda que não sejam identificados, ainda que permaneçam abertos à espera de uma identificação futura mais precisa. Algo que é um desafio, pois parece próprio do afeto justamente a infinidade de relações, de

\footnotetext{
* Doutor em Literatura pela Universidade Federal de Santa Catarina (UFSC). Professor do Programa de Pós-Graduação em Ciências da Linguagem da Universidade do Sul de Santa Catarina (UNISUL). E-mail: linck.alexandre@gmail.com.
} 
correspondências de força que ele põe em jogo. Como então proceder uma análise rigorosa do afeto, como formular um saber a partir da abertura daquilo que ganha rosto pela sarjeta? Quero, portanto, propor neste artigo um estudo de caso específico que, ao mesmo tempo, é bastante abrangente no que se refere às suas implicações. É o caso da relação entre o texto e a imagem, presente em tantas mídias, mas que possui toda uma tradição de discussões no estudo das histórias em quadrinhos. A pergunta que precisa ser feita é: quais os afetos, qual o rosto que aparece na sarjeta pressuposta entre a relação texto e imagem?

$\mathrm{Na}$ teoria dos quadrinhos, existe toda uma disputa histórica a respeito da relação imagem e texto como eventual forma de definição do ser da história em quadrinhos. A polarização ocorre entre aqueles que afirmam existir um hibridismo radical definidor dos quadrinhos e aqueles que o descartam por diferentes motivos. Neste ponto, muitas invenções, muitos conceitos forjados sobre os quadrinhos estão em jogo. Aqueles que apelam para a existência de uma natureza híbrida muitas vezes o fazem para ressaltar uma característica supostamente própria - e, por isso, digna de nota - das HQs, de modo a imprimir uma sofisticação. A estes, foge o fato de que jornais, cartazes, embalagens, dadaísmo, poesia concreta, videogames ou mesmo cinema (numa experiência tão pouco debatida que é o afeto de um filme legendado) são reconhecidamente "híbridos" - isto só para citar alguns. Da mesma forma, o argumento do hibridismo é utilizado para explicar a recusa da legitimação cultural e da valorização artística das HQs. Groensteen (2009) aponta que a natureza híbrida dos quadrinhos foi um dos principais fatores da sua histórica baixa autoestima. Esta nota tem como base a "ideologia da pureza" lançada por Lessing em seu Laocoonte ou Sobre os limites da pintura e da poesia, de 1766. A distinção categórica entre visual e verbal, ou entre temporal e espacial, de forma a purificar a pintura e a poesia para que estas, em sua autonomia, possam atingir seu próprio desenvolvimento, teria legado a uma arte mista, como os quadrinhos, uma estética corrompida. Mas Beaty (2012) contesta esta hipótese ao lembrar o hibridismo presente também na ópera e no balé, reforçando o argumento de que a explicação está menos no formal e mais no social, afinal, é compreensível que uma popularesca diversão publicada em jornais não obtivesse o mesmo glamour de um espetáculo ligeiramente caro para uma plateia mais restrita.

Seja como for, o que tais confrontações deixam em aberto é a afetividade que esse tal hibridismo entre texto e imagem tem com as histórias em quadrinhos. Ou seja, há um hibridismo, mas ele supostamente não afeta em nada a maneira como nos relacionamos com a imagem e o texto ao mesmo tempo. Por isso ocorrerá uma reação que Miodrag (2013) identifica como contraditória: a importância de um hibridismo que é indistinto à maneira coesa com que os quadrinhos são lidos/vistos. Fica a pergunta: ao presumir-se que existe uma interação, ou seja, que existem dois ou mais registros em jogo, qual o sentindo de ignorar as distinções que justamente atribuem elementos diferenciados no interior das HQs? A resposta a essa ignorância estratégica que misteriosamente faz dois serem iguais a um, segundo Miodrag, esconde o receio de que se dê munição para o argumento de que os quadrinhos são apenas a soma de prosa literária com arte gráfica, narrativa com decoração, ou qualquer outro amontoado de características que elimine uma tão almejada essência distintiva das HQs. Em parte, disto surge a concepção de 
"linguagem dos quadrinhos", como meio de unificar, exibir uma fala autônoma, que somente às HQs é dado o poder de falar. Cabe então a investigação de que, se existem distinções, é preciso considerar como elas são percebidas e, principalmente, o que afeta tal percepção.

Ocorre algo curioso com a análise dos quadrinhos, um tanto sintomático, mas que ajuda a desestabilizar algumas impressões. Carrier (2000) compara a relação textoimagem dos quadrinhos como a escultura do Hermafrodita, parte da coleção Borghese, exposta no Louvre. Segundo ele, com esta escultura, existe uma espécie de experiência desconcertante, excitante e/ou ameaçadora, de modo que, independentemente da pessoa do apreciador, o afeto reside na capacidade de trair categorias distintivas que dão chão à normalidade. "Daí a fascinação com, e medo de cross-dressing, androgenia, pessoas 'mestiças', quadrinhos, e outras formas de inter-valências" (CARRIER, 2000, p. 71, tradução minha). Já Miodrag (2013), ao falar de como a linguagem pode delinear a sensibilidade, sendo esta, posta em jogo pela relação texto-imagem nos quadrinhos, menciona Judith Butler e as questões de gênero. Questões estas que seriam levantadas publicamente no Brasil, nos últimos anos, por Laerte Coutinho, quadrinista que se assumiu cross-dresser, engajou-se na causa transgênero e depois fez uma resenha em quadrinhos do livro Judith Butler e a teoria queer, de Sara Salih. Além disso, Laerte publica, desde 2008, a tirinha Manual do Minotauro. Sem um personagem fixo, o Manual apresenta diferentes histórias, misturando humor, sátira política, autobiografia, fabulação e abstracionismo, sem se prender a um tema ou gênero específico. Porém, existe certa predominância poética sobre a mudança, não a romântica, que faz, em um passe de mágica, o sapo virar príncipe, mas aquela que está ainda em processo, prendendo-se no momento em que aquele corpo não é mais exatamente um sapo, mas também não é um príncipe ainda. Isso faz surgir corpos impermanentes, que deslocam partes, causam estranhamento, mesmo que bem-humorado.

Figura 1. Fonte: Laerte, Manual do Minotauro, 2014.

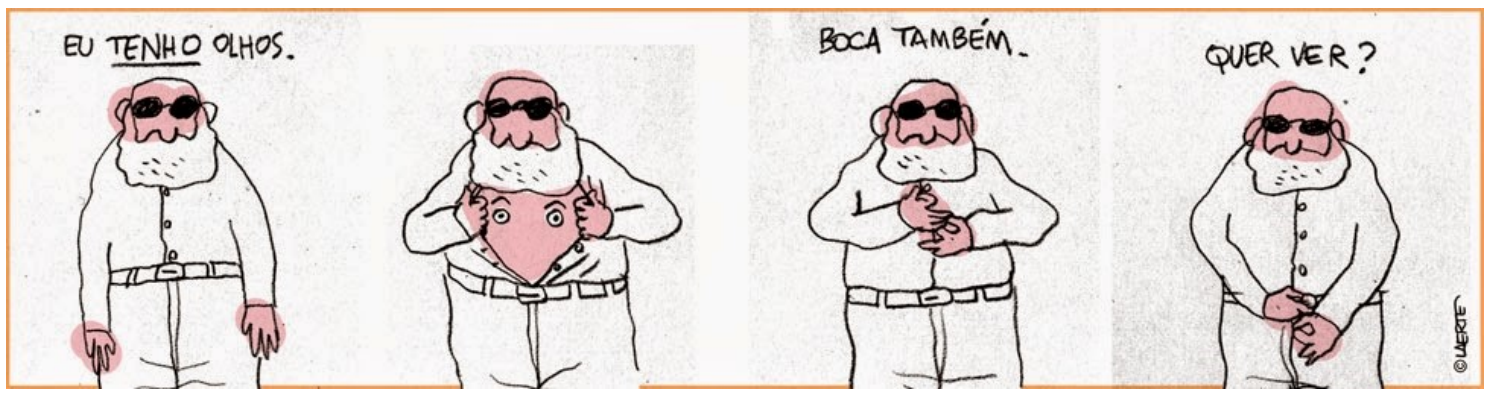

É o caso da tira de 08 de agosto de 2014, na qual um homem velho, careca, de espessa barba branca e óculos escuros, o que pode evidenciar cegueira, mostra seus olhos no lugar dos mamilos e nos desafia a mostrar sua boca no lugar da genitália. Não existe, nestes quatro momentos a marcação dos quadros, embora há muito suavemente uma textura escurecida que separa cada um. A cor rosada que demarca a pele não segue exatamente o contorno do traço, algo que dá a ela fluidez, uma espécie de segunda camada de desenho, e talvez impulsione ainda mais a sensação de deslocamento. Outra 
característica, nada incomum, mas digna de nota neste momento, é a ausência de balões ainda que reconheçamos a fala como sendo do personagem. Harvey (2009), um dos defensores da articulação texto-imagem como o radical dos quadrinhos, argumenta que a integração do texto com a imagem ocorreu em virtude do humor, pois a piada se tornava mais coesa e certeira a partir do momento em que o texto passasse a não ter mais a necessidade de descrever e, ainda que estivesse no rodapé do quadro, fosse dada aos personagens a possibilidade de falar.

$\mathrm{O}$ que as alusões ao hermafroditismo, mestiçagem, transgeneridade ou sobreposições têm a ver com o personagem que fala por si próprio, como na tira de Laerte, é a percepção de que a sarjeta entre a escrita e a figuração pode ser, ao contrário do que dizem, o mais forte vínculo de estabilidade diante de entremeios outros como partes do corpo fora do lugar, cores que não obedecem ao contorno ou balões e requadros ausentes. Em outras palavras, se existe um hibridismo, algo que coloca em interação ou junção dois elementos distintos, de forma ainda a deixar o rastro do que outrora foi dois, talvez este hibridismo esteja em outro lugar que não na relação texto-imagem.

Para argumentar a favor da relação texto-imagem como uma distinção inventada, Groensteen (2009) recorre a uma citação de Foucault sobre o caligrama, tradição milenar que "pretende apagar ludicamente as mais velhas oposições de nossa civilização alfabética: mostrar e nomear; figurar e dizer; reproduzir e articular; imitar e significar; olhar e ler" (FOUCAULT, 1988, p. 23). Desta forma, Groensteen acusa o hibridismo incômodo das HQs da invenção de uma cultura logocêntrica, de modo a resgatar a palavra grega graphéin, que significa "escrever" e também "pintar", assim como a experiência chinesa e a japonesa em que o cursar do pincel une a escrita e o desenho pela mesma mão com o mesmo instrumento. Mitchell (2009, p. 118, tradução minha) complementa que não existe arte ou mídia pura, que todas combinam "diferentes códigos, convenções discursivas, canais, modos sensoriais e cognitivos". O que costumeiramente sustenta estas argumentações é o caso das onomatopeias nos quadrinhos. Cirne (1977), no apelo poético que lhe era comum, chama esta característica dos quadrinhos de "voltagem onomatopaica": a intensidade com que palavras são revestidas de sua força gráfica, construindo uma sobreposição de convenções, seja do som motivado, seja de uma palavra estrangeira que se torna sinônimo de abstração sonora para outras culturas (como click, bang, crash etc). Nos anos 1960, houve um enorme interesse por onomatopeias, fosse pela Pop Art, com Ziraldo a elas se dedicando com Zeróis, fosse pela academia com análises de Umberto Eco, por um artigo de Naumim Aizen para a coletânea Shazam! ou pelo primeiro livro de Cirne sob o exclamativo nome Bum!. Isso levaria, principalmente a partir dos anos 1980, com os quadrinhos tornando-se massivamente "adultos", a uma recusa por diferentes autores da onomatopeia como recurso criativo - Alan Moore e David Lloyd a evitaram por completo em $V$ de Vingança. A onomatopeia muitas vezes foi vista como mais um sinal da pobreza literária dos quadrinhos, onde até mesmo sons não podiam ficar no plano da mera sugestão, precisando ser explicitados da maneira mais espalhafatosa possível. Por outro lado, aqueles que queriam afirmar uma sofisticação dos quadrinhos, davam-se ao trabalho de listar uma quantidade interminável de onomatopeias para evidenciar uma riqueza linguística e semântica. Por isso tudo, todos os bens e males 
se encontravam na onomatopeia dos quadrinhos cumprindo parte de sua função indicial ao ser indício, ela mesma, de HQs - inclusive da reunião do texto e da imagem.

Porém, Miodrag (2013) sustenta o seguinte ponto: embora todo texto seja também uma inscrição gráfica, sua recepção e seu processamento não são os mesmos da imagem. Ela retoma a oposição de Saussure, langue/parole, para falar de texto e imagem. Segundo a autora, o texto é langue, existindo por unidades mínimas (morfemas), de modo que seus signos são usados. Já a imagem é parole, não possui unidades mínimas, somente contextuais, por tal razão, seus signos são criados. Miodrag insiste que esta distinção, uma fricção entre o icônico e o simbólico, foge do interesse dos teóricos dos quadrinhos em parte por causa de uma "textofobia", que procura focar na supremacia da imagem, ou de sua iconicidade, evitando qualquer comparação com os livros ilustrados. Apesar de a autora em muito se opor a Scott McCloud (2005), ela edifica sua distinção texto-imagem de forma muito semelhante à do autor da teoria em quadrinhos Desvendando os quadrinhos.

Detemo-nos primeiramente na noção de imagem: "Imagens são informações recebidas. Ninguém precisa de educação formal pra 'entender a mensagem'. Ela é instantânea. A escrita é informação percebida. É preciso conhecimento especializado pra decodificar os símbolos abstratos da linguagem" (MCCLOUD, 2005, p. 49). O autor sustenta a mesma categoria semiótica corrente da imagem como ícone, de maneira a entendê-la como uma afirmação imediata de outra coisa. Por isso, nada mais natural do que a imagem ser somente recebida, sem qualquer intervenção possível do seu espectador, afinal, esse mesmo raciocínio entende que a realidade do ícone é imperativa. McCloud tenta levar isso mais longe, ao propor uma leitura do quadro de Magritte, A traição das imagens. Sua fácil solução para a frase "Isto não é um cachimbo" é: a imagem de um cachimbo não é um cachimbo, é um ícone.

Mas o que dizer da frase que nega o cachimbo? Para Foucault, a interação imagemtexto do quadro - e desenho - de Magritte é mais complexa do que isso. Ele sugere que "a figura [retém] em si a paciência da escrita e que o texto [é] apenas uma representação desenhada" (FOUCAULT, 1988, p. 25). Por isso sua alusão ao caligrama, pois enquanto "no caligrama jogavam, um contra o outro, um 'não dizer ainda' e um 'não mais representar"' (FOUCAULT, 1988, p. 28), em Magritte a imagem e o texto, certos do que mostram/dizem, apelam para a identificação por exclusão. Para Foucault, portanto, o caligrama lida, acima de tudo, com uma hesitação da ordem dos registros, de modo a desativar a distinção texto-imagem não por sua desconstrução, mas antes, na sua préconstrução de sentido. O caligrama é a sarjeta que separa o texto e a imagem na diagramação de uma página, lugar este onde acontecem "todas as relações de designação, de denominação, de descrição, de classificação. O caligrama reabsorveu esse interstício" (FOUCAULT, 1988, p. 33), de forma a explicitar não a indistinção da escrita e da figuração, mas de indefinir o que seguramente as dividia. É neste lugar obscuro, da distinção não mais esclarecida, que Magritte faz seu Cachimbo.

Segundo Foucault, dois princípios reinaram sobre a pintura ocidental do século XVI até o XX. "O primeiro afirma a separação entre representação gráfica (que implica a semelhança) e referência linguística (que a exclui)" (FOUCAULT, 1988, p. 39). Este princípio seria abolido por Paul Klee ao fazer do espaço uma incerteza entre tela e folha. 
"O segundo princípio que durante muito tempo regeu a pintura coloca a equivalência entre o fato de a semelhança e a afirmação de um laço representativo. [...] O essencial é que não se pode dissociar semelhança e afirmação" (FOUCAULT, 1988, p. 41, 42). A ruptura com isto seria feita por Kandinsky, pelo apagar da semelhança e do laço representativo com linhas, formas e cores dispostas como "coisas". Magritte, por sua vez, jogaria de forma distinta com esses dois princípios. Primeiro, por tornar seu objeto a explicitação da sarjeta entre a escrita que nega o cachimbo e do desenho do cachimbo que desmente a frase subscrita, segundo, por opor semelhança e similitude, não bastando o desenho de um cachimbo parecer um cachimbo, mas, pela confrontação, fazendo com que o desenho de um cachimbo se pareça com um cachimbo desenhado e que, ele próprio, pareça com a ideia de cachimbo. Da mesma forma, os enunciados verbais serão não afirmativos, o que "isto não é um cachimbo" diz afirmativamente é o que ele parece dizer, é a aparência de uma afirmação que pode ser traidora ou só parecer assim ser. O próprio Magritte (apud FOUCAULT, 1988, p. 82-83) diria: "Existe, há algum tempo, uma curiosa primazia conferida ao 'invisível' através de uma literatura confusa, cujo interesse desaparece ao se observar que o visível pode ser escondido, mas que o invisível não esconde nada: pode ser conhecido ou ignorado, sem mais". Não foi esta similitude do visível a obsessão de Andy Warhol? Da mesma forma, não seria a imagem reproduzida dos quadrinhos de Roy Lichtenstein, sobretudo as onomatopeias, a aparência do que uma HQ pode parecer?

O que interessa para um possível rosto dos quadrinhos em toda esta análise de Foucault sobre Magritte, além do fato de ele perturbar qualquer iconicidade simplista sobre o mesmo objeto evocado por McCloud, são dois tópicos precisos: a sarjeta entre a imagem e o texto, e a imagem da similitude na figuração. Neste artigo, o primeiro tópico será aquele ao qual me aterei mais. Para tanto, uma breve análise do balão dos quadrinhos parece necessária.

Mitchell (2009) chama atenção para o fato de que no mundo pré-cartesiano, a fala representada nas iluminuras dava-se por meio de filactérios que emanavam mais dos gestos do que da boca, da mesma forma que eram tridimensionais. Já o balão dos quadrinhos, que decorre das caricaturas desde o século XVIII - particularmente populares na Inglaterra (GROENSTEEN, 2009) -, tem como característica o vínculo com a boca ou o pensamento - por meio de bolhas - em um espaço bidimensional. Esta "fantasmagórica emanação de um invisível interior" (MITCHELL, 2009, p. 117, tradução minha) não está desvinculada do sujeito do conhecimento cindido na modernidade, na qual a linguagem se destaca de uma "natureza humana" para dela se assenhorar. Como consequência, a imagem encontra sua função no ponto em que supostamente a linguagem declina, isto é, na representação afirmativa de sua substância icônica, e a linguagem, na condição cartesiana de pensamento do mundo, assume a decifração do segredo dos símbolos, dessa coisa misteriosa chamada palavra, tarefa esta que só pertencia a Deus, homens-santos e profetas. É precisamente aqui que o símbolo e o ícone nascem, de modo a subdividir a responsabilidade sobre a verdade, seja ela a da escritura decifrada, seja ela da imagem observada. Por isso, o balão sofreria problemas para se estabelecer nos quadrinhos do século XIX, afinal, de que jeito o observado, imobilizado pela sua apreensão plástica e 
translúcido pela sua figura, poderia discursar, articular-se como sujeito da fala? Ademais, como fazer tudo isso sem perder sua beleza, pelo menos quando a beleza interessa?

É preciso considerar que na modernidade, no momento em que coube à escrita (e à leitura) a iniciativa do descobrimento do mundo, a imagem, para não sucumbir diante de uma passividade sepulcral, precisou, pela arte, resgatar o belo como seu próprio termo de empoderamento, exigindo da contemplação o critério de seu trabalho. Desta forma, se no medievo a imagem era a palavra, com a modernidade a imagem, desprovida de palavras, tinha no belo, fosse platônico, fosse aristotélico, a exigência de sua sensibilidade; se pela teleologia medieval o belo está em Deus na pintura, com $A$ criação de Adão, de Michelangelo, o belo está na pintura de Deus. Portanto, era de se esperar que um reencontro da palavra com a imagem fosse sinal de desconforto, de poderes ameaçados ao símbolo do conhecimento e ao ícone do belo. Smolderen (2014) chama atenção para esse desconforto, essa tensão traduzida nos quadrinhos, de maneira que a rispidez de um desenho que fala provavelmente fez com que as primeiras HQs declinassem a utilização de balões. Se na caricatura estavam em uso, os balões serviam muito mais ao absurdo, ao comentário sarcástico, ao humor de uma pirraça infantil que dá falas a imagens, vítimas imóveis de qualquer discurso a elas atribuídas. Não por acaso os balões, popularizados nos quadrinhos dos jornais americanos a partir de Yellow Kid, em 1896, avançariam sob a égide do humor, tendo com o Gato Félix, nos anos 1920, o exemplo mais famoso dessa autoconsciência debochada dos recursos das HQs. Nos anos 1930, quando os quadrinhos americanos aspiraram a um maior realismo e à seriedade suficiente de uma história de aventura, Hal Foster não usaria balões em seu Príncipe Valente, e Alex Raymond, depois de algum tempo, evitá-los-ia em seu Flash Gordon. Ainda assim, o balão persistiu como este objeto estranho, este algo bidimensional que costumeiramente é entendido como sobreposto à tridimensionalidade do desenho, dando a imagens estagnadas o movimento da fala.

Opondo ao que se chama "funções escritas" a privilégio de "funções verbais", Groensteen (2007) entende que o balão está mais ligado à oralidade do cinema do que à escrita da literatura. Este argumento sustenta-se sobre a concepção do diálogo no cinema a serviço de uma equivalência técnica da naturalidade do mundo. Para tanto, Groensteen cita Christian Metz no comentário de que, ao contrário da imagem cinematográfica, que é bidimensional e precisa simular uma tridimensionalidade, o som não possui esta necessidade de conversão. O problema principal desta teorização, e ao mesmo tempo a força de sua estratégia, é a mesma que sustenta a definição de Groensteen sobre os quadrinhos como "solidariedade icônica". Afinal, no instante em que as HQs se tornam uma "coisa" que se dá, sobretudo, pela iconicidade, é esperado que o som, ou melhor, a escrita, não seja enfatizada como aquela do símbolo, do arbitrário decifrado, mas do ícone da fala, da oralidade reproduzida, espelhada, como seria a do fonógrafo ocupado por um papagaio em 25 de outubro de 1896 em The Yellow Kid, imagem mítica do início dos balões (SMOLDEREN, 2014). Com isso, toda a potencialidade da escrita nas histórias em quadrinhos é delegada à funcionalidade de informação adicional de uma imagem icônica, e o balão torna-se apenas o invólucro desta conversão.

O que toda análise do balão no contexto da história da disjunção entre o texto e a imagem nos mostrou foi algo diferente. Não se trata de um reducionismo a categorias 
semióticas de ícone ou símbolo, nem de uma operação - impossível - de retorno a uma experiência medieval. O balão, assim como o que Foucault identificou em Magritte, não é a supressão das diferenças, mas o desafio da igualdade dos distintos, a explicitação de uma sobrevivência, de uma sarjeta onde o texto e a imagem caem, cada uma de acordo com seu peso, sobre um registro que os põem eternamente na convivência tensa de seu limiar. Na tira de Laerte analisada não há a presença de um balão, porém isso pouco importa. O que esta ausência nos ajuda a perceber é que a sarjeta que o balão eventualmente dá à imagem está perfeitamente esticada ao corpo dos próprios quadrinhos de maneira que a distinção imagem-texto é posta enquanto suporte. Em outras palavras, não é que exista uma tensão entre a imagem e o texto nos quadrinhos, mas é esta tensão, a própria qualidade desta tensão, dada como assegurada, conhecida, certa para toda uma tradição acostumada com a separação histórica entre texto-imagem que dá chão para a história em quadrinhos. É a sarjeta distendida que dá suporte para que uma HQ possa, então, partir para a busca de outras formas de tensão e sobreposição, como aquelas descritas na tirinha do Manual do Minotauro. A relação texto-imagem, ela mesma uma fenda, pode ser um rosto caso se deseje do afeto sua imagem.

É precisamente neste ponto, então, que o saber sobre o afeto ganha seu rigor ainda que na vertigem da indefinição. Pois, a relação texto-imagem que aparece em imagem, o rosto que se dá a um corpo inteiro - corpo do personagem da tira, corpo de toda a tira —, é, metonimicamente nos quadrinhos, o espaço de um acontecimento à sarjeta. Um afeto, afinal, que dá à percepção sua senciência de modo a operar na indistinção dos distintos - texto e imagem, símbolo e ícone, leitura e contemplação, rosto e corpo. É, portanto, por um cruzamento entre a filosofia do afeto e uma teoria da sarjeta que esta investigação deverá prosseguir - naquilo que devolve ao saber à sua capacidade criativa de afetar-se pela experiência de um não-saber.

\section{REFERÊNCIAS}

BEATY, Bart. Comics versus art. Toronto: University Of Toronto Press, 2012.

CARRIER, David. The aesthetics of Comics. Pennsilvania: Penn State Press, 2000.

CIRNE, Moacy. Bum! A explosão criativa dos quadrinhos. Petrópolis: Vozes, 1977.

DELEUZE, Gilles. A imagem-afecção. In: Cinema 1: a imagem-movimento. São Paulo: Brasiliense, 1983.

FOUCAULT, Michel. Isto não é um cachimbo. Rio de Janeiro: Paz e Terra, 1988.

GROENSTEEN, Thierry. The system of comics. Oxford: University Press of Mississippi, 2007.

Why are comics still in search of cultural legitimization? In: HEER, Jeet; WORCESTER, Kent

(Org.). A comics studies reader. Oxford: University Press of Mississippi, 2009.

HARVEY, Robert C. How comics came to be. In: HEER, Jeet; WORCESTER, Kent (Org.). A comics studies reader. Oxford: University Press of Mississippi, 2009.

LAERTE. Manual do Minotauro: 08-08-2014. 2014. Disponível em:

$<$ http://manualdominotauro.blogspot.com.br/2014/09/08-08-2014.html>.

MCCLOUD, Scott. Desvendando os quadrinhos. São Paulo: M. Books, 2005.

MIODRAG, Hannah. Comics and language: reimagining critical discourse of the form. Oxford: University Press of Mississippi, 2013.

MITCHELL, W. J. T. Beyond comparison. In: HEER, Jeet; WORCESTER, Kent (Ed.). A comics studies reader. Oxford: University Press of Mississippi, 2009.

SMOLDEREN, Thierry. The origins of comics: from William Hogarth to Winsor McCay. Oxford: University Press of Mississippi, 2014. 
Recebido em 04/02/2016. Aprovado em 04/03/2016.

Title: Affects at the gutter: the between place of text and image

Abstract: A theory of affects at the gutter. In order to understand with some accuracy the quality-potency of the affect, this article presents a case study of the relationship between text and image, especially in comics. Thereby, it seeks to provide support for the questions of identification, knowledge and event, places of affections in the space between written word and figurative image. Therefore, it will be offered the concept of gutter, a place where something passes to another, an interval for which an invisible event can be viewed. It is through the face of the printed affect at the gutter of the relationship text-image that this research will start.

Keywords: Affect. Gutter. Comics.

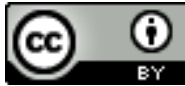

Este texto está licenciado com uma Licença Creative Commons Atribuição 4.0 Internacional. 